\title{
Impact of Obesity and Bariatric Surgery in the Outcome of Patients with Heart Failure
}

\author{
Ricardo Mourilhe-Rocha ${ }^{1,2}$ and Nathália Felix Araujo Salvino ${ }^{2,3}$ \\ Hospital Universitário Pedro Ernesto, ${ }^{1}$ Rio de Janeiro, RJ - Brazil \\ Hospital Pró-Cardíaco, ${ }^{2}$ Rio de Janeiro, RJ - Brazil \\ Associação Brasileira de Nutrologia - ABRAN, ${ }^{3}$ Catanduva, São Paulo - Brazil
}

\section{Abstract}

Currently, the association between obesity and heart failure (HF) is increasingly known. Patients with advanced obesity who suffer from HF without an identifiable cause can be diagnosed as having obesity-associated cardiomyopathy. Although data suggest that obesity may reduce mortality in $\mathrm{HF}$, weight loss, especially in the presence of morbid obesity, reduces symptoms and improves the quality of life of those patients.

Bariatric surgery is the major treatment available for sustained weight loss in morbid obesity. Observational studies have demonstrated an improvement in ventricular structure and function of morbidly obese patients with HF who underwent that procedure.

Thus, despite the risks, bariatric surgery should be considered for patients with HF, because of its potential for reducing associated comorbidities and improving quality of life and functional capacity, in addition to making eligible for heart transplantation those excluded due to high body mass index.

\section{Introduction}

The prevalence of obesity has reached epidemic proportions globally and is associated with generalized alterations in the cardiovascular structure and function. ${ }^{1}$ On the other hand, the prevalence of heart failure (HF) is approximately $1 \%$ to $2 \%$ of the adult population of developed countries, and HF is one of the major causes of hospitalization, morbidity and mortality among the

\section{Keywords}

Hypertrophy, Left Ventricular; Heart Failure; Obesity; Bariatric Surgery; Comorbidity; Quality of Life. elderly ( $\geq 65$ years). ${ }^{2}$ In Brazil, according to the BREATHE study, ${ }^{3}$ coronary artery disease is the major cause of HF $(30.3 \%)$, whose major causes of decompensation are poor medication adherence (30.0\%), infections $(23.0 \%)$ and inadequate control of water and sodium ingestion (9.0\%). ${ }^{3}$

Heart failure is currently known to be associated with obesity, ${ }^{2,-15}$ regardless of the presence of comorbidities, such as arterial hypertension ( $\mathrm{AH})$ and coronary artery disease. ${ }^{16,17}$ The Framingham Heart Study reports that to every $1-\mathrm{kg} / \mathrm{m}^{2}$ increase in body mass index (BMI), the risk of developing HF increases by $5.0 \%$ in men and by $7.0 \%$ in women. ${ }^{8}$ In addition to BMI, waist circumference and waist-hip ratio have been shown to be associated with HF in several cross-sectional and prospective studies. ${ }^{12}$

Obese individuals have a two-fold increased risk of premature death as compared to non-obese individuals, in addition to a five-fold increased risk of death from cardiovascular disease. ${ }^{18}$ That risk factor is also related to the higher incidence of atrial and ventricular arrhythmias ${ }^{15}$ and sudden death. ${ }^{5}$ Furthermore, obesity has frequent associations, such as systemic $\mathrm{AH}$, diabetes mellitus (DM), dyslipidemias and sleep obstructive apnea, increasing even more the likelihood of cardiac impairment. ${ }^{19}$

Left ventricular hypertrophy (LVH) is the major cardiac morphological change related to obesity, ${ }^{10,20}$ while diastolic dysfunction is the major functional change, manifested as elevated left ventricular (LV) end-diastolic pressure..$^{10}$ Obesity produces a variety of hemodynamic changes that can predispose to left and right ventricular dysfunction, even in the absence of cardiac comorbidities, a condition known as obesity cardiomyopathy. ${ }^{20}$ Most obese patients with HF have preserved ejection fraction. ${ }^{20}$ Thus, in the presence of LV systolic dysfunction, other associated etiologies should be sought. 
There is little evidence of the long-term beneficial effect of intentional non-surgical little weight loss on the outcome of HF. However, observational studies have shown that bariatric surgery has a beneficial effect on ventricular structure and function in morbidly obese individuals ${ }^{21}$ with HF with preserved ejection fraction (HFpEF) or HF with reduced ejection fraction (HFrEF). ${ }^{22}$ Bariatric surgery is currently the major treatment available that leads to sustained weight loss and significant improvement or complete resolution of morbid obesity-related comorbidities., ${ }^{2,21}$ Understanding the safety and feasibility of that procedure in patients at higher surgical risk is fundamental.

\section{Objective}

This review was aimed at describing the relationship between obesity and $\mathrm{HF}$, as well as the safety and benefits of bariatric surgery in obese patients.

\section{Methods}

This study comprised the review of the literature in the PubMed database over the last 15 years. The following terms were used: "obesity and heart failure and bariatric"; and "bariatric surgery and cardiac alterations". The search retrieved 139 publications, after excluding duplicates. After excluding the articles not related to the topic studied, 47 articles were selected for analysis (Figure 1).

The European Guideline for the Treatment of Obesity in Adults was used to define and classify obesity. ${ }^{23}$ According to that guideline, for adults aged $>18$ years, overweight or preobesity is characterized by a BMI between 25 and $29.9 \mathrm{~kg} / \mathrm{m}^{2}$, and obesity is characterized by a BMI $\geq 30 \mathrm{~kg} / \mathrm{m}^{2}$, being subdivided into grade I $\left(B M I=30-34.9 \mathrm{~kg} / \mathrm{m}^{2}\right)$, grade II $\left(B M I=35-39.9 \mathrm{~kg} / \mathrm{m}^{2}\right)$, and grade III or morbid obesity $\left(\mathrm{BMI} \geq 40 \mathrm{~kg} / \mathrm{m}^{2}\right){ }^{23}$

Heart failure was defined according to the European Guideline for the Diagnosis and Treatment of Acute and Chronic Heart Failure. ${ }^{24}$ Heart failure is a clinical syndrome characterized by typical symptoms, such as dyspnea, lower limb edema and fatigue, which can be accompanied by signs, such as jugular venous distension and pulmonary rales caused by cardiac structural and/ or functional abnormality, resulting in reduced cardiac output and/or high intracardiac pressures at rest or during stress.

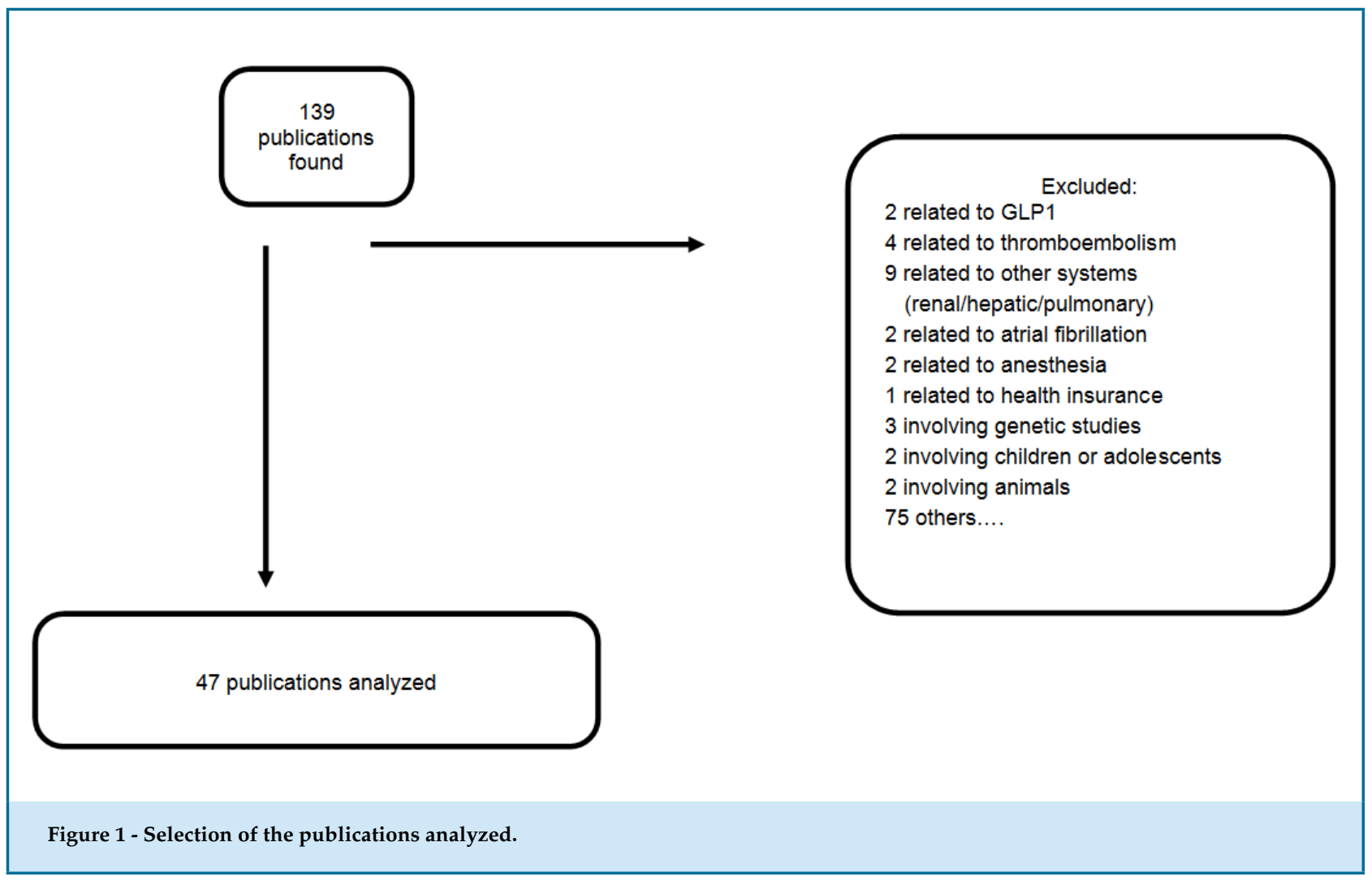


Traditionally the major parameter to differentiate the subtypes of HF is LV ejection fraction. That guideline stratifies patients into three groups: HFpEF - those with ejection fraction $\geq 50 \%$; HFrEF - those with ejection fraction $<40 \%$; and mid-range ejection fraction - those with ejection fraction between $40 \%$ and $49 \%$, considered to be in a gray zone between the two others. ${ }^{24}$ This differentiation is essential for the treatment strategies.

To keep the uniformity with most publications analyzed in this review, patients with HFpEF were those with an ejection fraction $\geq 50 \%$, while patients with HFrEF were those with an ejection fraction $<50 \%$.

Hemodynamic and morphological changes associated with obesity

Although since the $17^{\text {th }}$ century the heart of obese individuals has been known to be "enlarged, thick and fibrous", it was only in 1933 that global myocardial hypertrophy, in the absence of hypertension, was reported for the first time in obesity. ${ }^{9}$

It is currently known that, in severe obesity, cardiac output is increased at the expense of increased circulating volume, leading to a state of chronically elevated preload, which favors the increase of ventricular dimensions, of parietal stress and LV mass. ${ }^{8,12,14,25,26}$ This set of chronic hemodynamic changes can lead to cardiac structural impairment with cardiac performance loss.

The most common change in cardiac morphology related to obesity is LV mass increase, directly related to the development of diastolic dysfunction in obesity. ${ }^{20}$ In addition to correlating with obesity, that change correlates with obesity duration. ${ }^{8}$ The Framingham Heart Study has shown that BMI is an independent predictor of LV mass, mainly when BMI exceeds $30 \mathrm{~kg} / \mathrm{m}^{2}{ }^{2}{ }^{14}$

The literature is highly controversial regarding the LVH pattern related to obesity. Recent studies, however, have suggested that, in obese individuals, concentric $\mathrm{LVH}$ and remodeling are as frequent as, or even more frequent than, eccentric LVH. ${ }^{10,27}$

Mild LV systolic dysfunction can be present, but moderate to severe systolic dysfunction is rare and should trigger the search for comorbidities not directly related to obesity. ${ }^{10,20}$

The presence of cardiac fibrosis in obese individuals is another important component of ventricular remodeling, increasing myocardial stiffness and diastolic dysfunction, resulting in clinical HF. Although it is important to recognize that such change can result from multiple conditions frequently associated with obesity, such as $\mathrm{AH}$, dyslipidemia and $\mathrm{DM}$, some studies have shown that fibrous remodeling of the ventricles resulting in significant diastolic dysfunction can occur in the absence of those comorbidities. ${ }^{8}$

Factors that contribute to LV systolic dysfunction in obesity include overload conditions, duration of obesity, LV mass increase, and comorbidities, such as coronary artery disease, $\mathrm{AH}$ and DM. ${ }^{20}$ In addition, the direct toxic effects of the excessive amount of adipose tissue might be related to ventricular remodeling, potentialized by insulin resistance and neurohumoral activation, particularly the renin-angiotensin-aldosterone system and the sympathetic nervous system. ${ }^{26}$

Another structural change frequently related to obesity is left atrial enlargement. ${ }^{14,20} \mathrm{~A}$ study has reported left atrial enlargement in $34.0 \%$ of obese individuals and in only $6.0 \%$ of normal-weight patients. ${ }^{20}$ Factors predisposing to left atrial enlargement in obesity include volume overload, LVH and LV diastolic dysfunction. ${ }^{14,20}$

Cardiac structural changes can be present even without any clinical sign of heart disease, representing a subclinical manifestation of obesity cardiomyopathy. A cross-sectional study, ${ }^{25}$ assessing 30 candidates for bariatric surgery with no history of previous heart disease, has reported enlarged left chambers in $42.9 \%$, diastolic dysfunction in $54.6 \%$, and $\mathrm{LVH}$ in $82.1 \%$, with the eccentric pattern of $\mathrm{LVH}$ present in half of the cases. The correlations between LVH, obesity duration and blood pressure levels were positive, as were the correlations between BMI and the diastolic dysfunction indicators. Systolic dysfunction was found in only $10.7 \%$ of the population studied..$^{25}$ The authors have concluded that ventricular mass adjusted for height can be more precise than ventricular mass adjusted for body surface area, and the former might be a more appropriate index to determine ventricular hypertrophy in obese individuals. ${ }^{14,25}$ Likewise, Tavares et al., ${ }^{28}$ have found higher sensitivity for the diagnosis of LVH in obese individuals when adjusting LV mass for height as compared to body surface area. ${ }^{28}$

\section{Obesity cardiomyopathy}

Patients with advanced obesity and HF with no identifiable cause of LV dysfunction can be diagnosed with obesity cardiomyopathy. ${ }^{5,6}$

That condition is defined as HF totally or predominantly due to obesity. ${ }^{20}$ The diagnosis can be difficult because 
symptoms of HF, such as fatigue and lower limb edema, can be frequently found in obese individuals. In addition, brain natriuretic peptide (BNP), an important marker commonly used in the diagnosis and follow-up of HF, has a limited use in obesity, ${ }^{6,12}$ and its levels are inversely proportional to $\mathrm{BMI}$, independently of the presence or severity of HF. ${ }^{6}$

In the Framingham Heart Study with 5,881 participants, $11.0 \%$ of the HF in men and $14.0 \%$ of the HF in women were solely attributed to obesity, even after adjusting for other known cardiovascular risk factors. ${ }^{8}$

The duration of morbid obesity is the strongest predictor of HF development in obese patients. ${ }^{6,26}$ The presence of morbid obesity for 20 years is associated with a $70 \%$ chance of developing $\mathrm{HF}$, which increases to $90 \%$ after 30 years. $^{9}$

Most publications analyzed in this review used the term 'obesity cardiomyopathy', encompassing all patients with preserved and reduced ejection fraction.

\section{Obesity paradox}

Several studies have shown a paradoxical association between obesity and the prognosis of patients with coronary disease and $\mathrm{HF}$, called the paradox of obesity. 5,-9,12,29 According to that theory and contrary to what is expected, individuals with established cardiac disease and overweight or obesity have a better prognosis than under- or normal-weight individuals. 5,7,8,12,30

That favorable prognosis is observed for both men and women, in acute HF, HFpEF and HFrEF. ${ }^{9}$ However, obesity hinders the treatment of patients with advanced $\mathrm{HF}^{8}$ and both morbid obesity and $\mathrm{HF}$ markedly reduce functional capacity. ${ }^{17}$ In addition, no study has reported that weight-reducing interventions of patients with morbid obesity increase the mortality or morbidity of $\mathrm{HF}^{4}$

A meta-analysis ${ }^{8}$ has shown a reduction in the hospitalization and cardiovascular and all-cause mortality of patients with HF and overweight as compared to those of patients with normal BMI. However, more severely obese patients have not had the same benefit. ${ }^{8}$ Other studies have suggested that when BMI exceeds $40 \mathrm{~kg} / \mathrm{m}^{2}$, obesity is once again associated with worse prognosis. ${ }^{9}$

There are several theories to explain that paradox, whose mechanism remains unclear. Observational studies demonstrating that paradox have not proven that weight loss is beneficial to obese patients with coronary artery disease, because most of them analyzed only baseline body weight values, with no follow-up data. ${ }^{5}$ In addition, most of them are retrospective analysis. ${ }^{9}$ Another relevant factor is that low BMI values are frequently associated with sarcopenia, a condition associated with increased mortality. It is postulated that, because BMI does not distinguish fat from lean mass, individuals with coronary artery disease and overweight or obesity can have a higher amount of preserved muscle mass. Thus, when BMI reaches very high values that direct to body adiposity, the obesity paradox disappears. ${ }^{5}$ Supporting that theory, studies using other measures to assess obesity and the prognosis of $\mathrm{HF}$, such as Dual-Energy X-Ray Absorptiometry (DEXA), ${ }^{9}$ have attained more controversial results.

On the other hand, obese individuals with HF can be diagnosed earlier, at a stage of lower myocardial dysfunction, than non-obese individuals, ${ }^{7-9}$ causing the impression of better cardiovascular outcome.

In addition, cardiac cachexia, which occurs late in $\mathrm{HF}$, is associated with worse prognosis. ${ }^{7-9,12}$ Thus, once advanced HF becomes catabolic, causing muscle mass loss and cachexia, obesity can progress with increased metabolic reserves in the form of adipose tissue, which can delay the catabolic stage. However, further investigation is required to determine if that is a mechanism. ${ }^{9,12}$

Although the obesity paradox can represent a statistical phenomenon, the likelihood of a real protective effect on the physiology of obesity should be considered. ${ }^{7,8}$

\section{Cardiac morphofunctional benefits related to weight reduction}

Substantial weight loss has been associated with the reversion of hemodynamic abnormalities and with the reverse LV remodeling of patients with obesity and HF. ${ }^{4,21,31}$ There is a linear relationship between weight loss and LV mass regression, ${ }^{14,32}$ in addition to the improvement of functional capacity. ${ }^{33}$

Bariatric surgery has been more successful than diet and exercise to reverse those alterations. Because it is used for patients with more severe obesity, it produces substantial weight reduction and more evident neurohormonal and metabolic improvement than the weight loss modalities based on diet and exercise usually used for less obese individuals. ${ }^{20}$

There is evidence that surgical weight reduction can increase ejection fraction in the presence of previous systolic dysfunction, ${ }^{1,10,17,34}$ mainly in individuals with long- 
term morbid obesity. ${ }^{21}$ Nevertheless, non-surgical weight reduction has shown that benefit in smaller studies. ${ }^{6}$

A recent study ${ }^{35}$ assessing high-sensitivity troponin I, a marker of subclinical myocardial injury, has suggested that weight loss following bariatric surgery may reduce cardiometabolic stress and the subsequent risk for HF. That study has assessed the impact of bariatric surgery versus lifestyle intervention, in isolation, in patients with morbid obesity. The patients submitted to bariatric surgery had a significantly higher reduction in highsensitivity troponin I than those undergoing the intensive lifestyle intervention. ${ }^{35}$

A clinical study, ${ }^{19}$ assessing 23 obese class-III or class-II individuals with preoperative comorbidities six months and three years after bariatric surgery, has reported the predominance of LVH prior to surgery. Three years after, the normal pattern predominated. In addition, LV diastolic function improved in six months, remaining so for three years. ${ }^{19}$

Another study, ${ }^{36}$ assessing 60 women with BMI $\geq$ $40 \mathrm{~kg} / \mathrm{m}^{2}$ by using echocardiography before and six months after bariatric surgery, has concluded that the weight loss following the procedure improved ventricular diastolic function and cardiac morphology in morbidly obese women. ${ }^{36}$

A cohort study, ${ }^{37}$ assessing, in a 10-year follow-up, 44 Swedish obese individuals submitted to bariatric surgery and compared to two control groups (nonsurgical obese patients and non-obese patients), has shown that the left ventricle adapts to long-term sustained weight loss, progressing to a smaller cavity, thinner walls and smaller ventricular mass. ${ }^{37}$ Another study by those same authors has reported that patients with sustained weight loss have superior LV systolic and diastolic functions as compared to their obese counterparts remaining weight stable. ${ }^{38}$

A recent study ${ }^{2}$ based on the Swedish National Patient Registry has assessed 47,859 patients with the primary diagnosis of obesity from 2000 to 2011, and compared those submitted to bariatric surgery ( $\mathrm{n}=22,295 ; 46.6 \%)$ to those not submitted to surgery $(\mathrm{n}=25,564 ; 53.4 \%)$. The result has shown an almost five-fold increased incidence of HF in non-surgical obese patients as compared to the obese patients submitted to bariatric surgery. This suggests that bariatric surgery can prevent HF in severely obese patients. ${ }^{2}$ Similarly, another study ${ }^{13}$ has assessed the efficacy of gastric bypass versus intensive lifestyle treatment to prevent
HF in obese individuals from two large registries, evaluating almost 40,000 patients: 25,804 treated with gastric bypass and 13,701 submitted to lifestyle change. The first group lost more weight than the second one, and, in a mean follow-up of 4.1 years, had a lower incidence of HF. In addition, an inverse relationship between weight loss and HF incidence was observed. ${ }^{13}$

\section{Bariatric surgery in heart failure: safety and benefits}

Bariatric surgery has been safely performed in obese patients with HF and optimized pharmacological treatment. Patients with manifest systolic HF and severe obesity improved their ejection fraction and functional capacity after bariatric surgery. ${ }^{1,12,34}$

There are several techniques of bariatric surgery: restrictive techniques, such as adjustable gastric band and vertical gastrectomy; and mixed techniques, with restrictive and disabsorptive components, such as gastric bypass. The latter has been the most frequently used in most publications analyzed in this review. The laparoscopic access has been shown to be a safe alternative for high-risk patients. ${ }^{39}$

More than half of the patients submitted to bariatric surgery, mainly gastric bypass, lose at least $50 \%$ of excessive weight. ${ }^{5}$ A case-control study ${ }^{4}$ conducted in three North-American states has assessed the rate of emergency unit visits or hospitalization due to HF worsening for four consecutive years, two years before and two years after bariatric surgery, in a sample of 534 patients with HF. That study has concluded that bariatric surgery is associated with a decline in the rate of HF worsening that requires emergency unit assessment or hospitalization. The study has not identified the subtypes of HF.,40

Recently, Vest et al., ${ }^{1}$ have compared 42 obese patients with LV systolic dysfunction (ejection fraction $<50 \%$ ), who had undergone bariatric surgery, with 2,588 obese patients without known ventricular systolic dysfunction submitted to the same procedure. The first group showed a higher baseline prevalence of comorbidities and a mild increase in HF and infarction in the early postoperative period, but no increase in 1-year mortality. In addition, the analysis of a subgroup of 38 patients with $\mathrm{HF}$, who underwent preoperative and postoperative echocardiography, has evidenced ejection fraction improvement, showing the safety and benefit of that procedure in those patients. ${ }^{1,10}$ 
A retrospective study ${ }^{17}$ has assessed 12 patients with morbid obesity and HFrEF (ejection fraction = $22 \pm 7 \%$ ) submitted to bariatric surgery and has compared them with a control group of 10 patients not submitted to surgery, who received diet and physical exercise orientation. In one year, the first group showed a lower incidence of rehospitalization and an improvement in functional capacity and ejection fraction as compared to the control group. One patient underwent successful transplantation, and another entered the transplant list, showing the importance of considering that procedure for patients with morbid obesity and HF. ${ }^{17}$

However, a recent retrospective analysis ${ }^{41}$ of 22,487 patients submitted to bariatric surgery has tried to identify the major risk factors for 1-year mortality, evidencing that, despite the low absolute risk of mortality, an increase in the relative risk was associated with open surgery, DM, male sex and HF. ${ }^{41}$ Other authors have associated the last two risk factors with increased mortality. ${ }^{42,43}$

\section{Bariatric surgery in patients with advanced HF}

In obese patients with advanced HF, BMI increase has been strongly associated with a lower probability of receiving heart transplantation, once added to the transplant waiting list. In addition, a BMI $\geq 35 \mathrm{~kg} / \mathrm{m}^{2}$ is related to a worse prognosis after heart transplantation, which is considered a significant obstacle to placement in the transplant list. ${ }^{8,34}$ The International Society of Heart and Lung Transplantation listing criteria ${ }^{44}$ recommend a weight loss that achieves a BMI $\leq 35 \mathrm{~kg} / \mathrm{m}^{2}$ before placement in the heart transplantation list. ${ }^{1,44}$ In obese patients with ventricular systolic dysfunction, surgical weight loss results in reverse ventricular remodeling. Thus, bariatric surgery is a strategy for weight reduction to be considered, as a bridge to heart transplantation or a path to clinical recovery. $17,26,34,45-47$

A study ${ }^{45}$ has reported that two patients with morbid obesity and severely reduced LV function, in addition to NYHA class IV symptoms, despite optimized medical treatment, one of them being dobutamine-dependent, were referred for bariatric surgery. Heart transplantation was initially contraindicated due to severe obesity. In the 2-year postoperative follow-up, both showed LV ejection fraction improvement, were symptomless and required no transplantation. ${ }^{26,45}$

Another study ${ }^{34}$ has assessed seven obese patients with LV ejection fraction $\leq 25 \%$, who had undergone laparoscopic bariatric surgery to become eligible for heart transplantation, because a BMI $\geq 35 \mathrm{~kg} / \mathrm{m}^{2}$ is considered a relative contraindication for that procedure. Later, two patients lost sufficient weight to undergo heart transplantation, two other lost sufficient weight to meet the listing criteria, and three improved their LV ejection fraction and symptoms, so transplant listing was no longer indicated. The individuals not submitted to transplantation had a median LV ejection fraction in the follow-up of $30 \%$ (mean of 39\%)., ${ }^{1,34}$

Traditionally LV assist devices (LVAD) are used as a bridge to transplant or "destination therapy" in individuals with advanced HF, despite maximum pharmacological therapy. ${ }^{26}$

Currently, data on the impact of obesity on the efficacy of those devices are limited. ${ }^{8}$ There is evidence that the LVAD implantation is safe, ${ }^{26}$ although a BMI increase has been associated with a higher chance of infection and thrombosis. However, the studies are scarce and have no power to determine the impact of BMI on mortality in those individuals. ${ }^{8}$

A recent analysis ${ }^{8}$ of the United Network for Organ Sharing database with 3,856 patients who had received a continuous-flow LVAD between 2004 and 2014 has shown that the risk of death or exclusion from the heart transplant waiting list did no significantly differ in patients with different BMI. However, complications, such as thrombosis and infection of the device, were significantly more frequently observed in patients with increased BMI (risk rate of 1.48 for patients with BMI > $35 \mathrm{~kg} / \mathrm{m}^{2}$ ). In addition, there was an increased risk of mortality after heart transplantation for obese patients as compared to that for patients with normal BMI. ${ }^{8}$

In 2013, the concurrent use of bariatric surgery and LVAD in a morbidly obese patient as a bridge to successful heart transplantation was reported for the first time. ${ }^{48}$ The concurrent use of that device and bariatric surgery allowed the patient to lose weight and subsequently qualify for placement in the heart transplant waiting list. ${ }^{48}$

In 2015 a review ${ }^{49}$ was published with six morbidly obese patients with advanced systolic HF, three of whom had a LVAD in place at the time of laparoscopic sleeve gastrectomy. Within 12 months of surgery, all patients had lost weight to become heart transplant eligible, considering their BMI. After subgroup analysis, the patients with LVAD, as compared to those without mechanical circulatory support, had a slightly longer 
operative time, greater estimated blood loss, and longer length of hospital stay. By the end of the study period, two patients with LVAD had undergone heart transplantation, one of whom died due to antibodymediated rejection three years after transplantation. Two patients were on the transplant list; one patient had a marked improvement in symptoms, being treated clinically; and the other patient was not eligible for transplant because of severe depression. ${ }^{49}$

There are other reports on successful cases involving LVAD and bariatric surgery as bridge for heart transplantation ${ }^{50,51}$ or improvement in ventricular function in morbidly obese patients. ${ }^{52}$

Most references presented in this review showed good results for bariatric surgery in patients with HF. However, it is worth noting that most studies cited were on interventions primarily directed to treat obesity and not eventual cardiac dysfunction, either clinical or suggested by different assessment methods.

\section{Conclusion}

Although some data suggest that obesity can provide a reduction in mortality of individuals with $\mathrm{HF}$, weight loss, especially in the presence of morbid obesity, reduces symptoms and improves the quality of life of those patients. In addition, it provides reverse remodeling and increases LV ejection fraction in the presence of systolic dysfunction, in addition to enabling heart transplantation to eligible individuals.

Bariatric surgery is an effective mean of weight loss. In patients with severe LV systolic dysfunction, however, although several studies have shown safety and efficacy, that procedure can be associated with severe complications and should only be performed in centers with trained specialists and advanced cardiac support involving multiple specialties.

\section{References}

1. Vest AR, Patel P, Schauer PR, Satava ME, Cavalcante JL, Brethauer S, et al. Clinical and echocardiographic outcomes after bariatric surgery in obese patients with left ventricular systolic dysfunction. Circ Heart Fail. 2016;9(3):e002260.

2. Persson CE, Björck L, Lagergren J, Lappas G, Giang KW, Rosengren A. Risk of heart failure in obese patients with and without bariatric surgery in Sweden-A Registry-Based Study. J Card Fail. 2017;23(7):530-7.
Most studies assessed have subdivided the analysis regarding neither etiology, nor the HF model, be it HFrEF or HFpEF. Future studies should assess the different models and etiologies in an individualized way and identify the most adequate surgical strategies.

Thus, despite the risks, bariatric surgery should be considered for patients with HF, because of its potential to reduce the associated comorbidities and to improve quality of life and functional capacity, in addition to making eligible for heart transplantation those excluded due to high BMI.

\section{Author contributions}

Conception and design of the research: MourilheRocha R, Salvino NFA. Acquisition of data: MourilheRocha R, Salvino NFA. Analysis and interpretation of the data: Mourilhe-Rocha R, Salvino NFA. Writing of the manuscript: Mourilhe-Rocha R, Salvino NFA. Critical revision of the manuscript for intellectual content: Mourilhe-Rocha R, Salvino NFA.

\section{Potential Conflict of Interest}

No potential conflict of interest relevant to this article was reported.

\section{Sources of Funding}

There were no external funding sources for this study.

\section{Study Association}

This study is not associated with any thesis or dissertation work.

\section{Ethics approval and consent to participate}

This article does not contain any studies with human participants or animals performed by any of the authors.

3. Albuquerque DC, Neto JD, Bacal F, Rohde LE, Bernardez-Pereira $\mathrm{S}$, Berwanger $\mathrm{O}$, et al; Investigadores Estudo BREATHE. I Brazilian Registry of heart failure - clinical aspects, care quality and hospitalization outcomes. Arq Bras Cardiol. 2015;104(6):433-42. Erratum in: Arq Bras Cardiol. 2015;105(2):208

4. Shimada YJ, Tsugawa Y, Brown DF, Hasegawa K. Bariatric surgery and emergency department visits and hospitalizations for heart failure 
exacerbation: population-based, self-controlled series. J Am Coll Cardiol. 2016;67(8):895-903.

5. López-Jiménez F, Cortés-Bergoderi M. Update: systemic diseases and the cardiovascular system (i): obesity and the heart. Rev Esp Cardiol. 2011;64(2):140-9.

6. Wong C, Marwick TH. Obesity cardiomyopathy: diagnosis and therapeutic implications. Nat Clin Pract Cardiovasc Med. 2007;4(9):48090.

7. Reigle J. Heart failure, obesity and bariatric surgery. Prog Cardiovasc Nurs. 2009;24(1):36-8

8. Zhai $\mathrm{AB}, \mathrm{Haddad}$ H.The impact of obesity on heart failure. Curr Opin Cardiol. 2017;32(2):196-202.

9. Rayner JJ, Neubauer S, Rider OJ. The paradox of obesity cardiomyopathy and the potential for weight loss as a therapy. Obes Rev. 2015;16(8):679-90.

10. Alpert MA, Pritchett AM. Bariatric surgery in patients with left ventricular systolic dysfunction: effective, but is it safe? Circ Heart Fail 2016;9(3):e002960.

11. Weismann D, Wiedmann S, Bala M, Frantz S, Fassnacht M. [Obesity and heart failure]. Internist (Berl). 2015;56(2):121-6.

12. Vest AR, Young JB. Should we target obesity in advanced heart failure? Curr Treat Options Cardiovasc Med. 2014;16(2):284.

13. Sundström J, Bruze G, Ottosson J, Marcus C, Näslund I, Neovius $\mathrm{M}$. Weight loss and heart failure: a nationwide study of gastric bypass surgery versus intensive lifestyle treatment. Circulation. 2017;135(17):1577-85.

14. Grapsa J, Tan TC, Paschou SA, Kalogeropoulos AS, Shimony A, Kaier $\mathrm{T}$, et al. The effect of bariatric surgery on echocardiographic indices: a review of the literature. Eur J Clin Invest. 2013;43(11):1224-30.

15. Badimon L, Bugiardini R, Cenko E, Cubedo J, Dorobantu M, Duncker DJ, et al. Position paper of the European Society of Cardiology - working group of coronary pathophysiology and microcirculation: obesity and heart disease. Eur Heart J. 2017;38(25):1951-8.

16. Frantz S, Fassnacht M, Allolio B, Bauersachs J. [Obesity and heart failure]. Internist (Berl). 2008;49(4):389-90, 392-3.

17. Ramani GV, McCloskey C, Ramanathan RC, Mathier MA. Safety and efficacy of bariatric surgery in morbidly obese patients with severe systolic heart failure. Clin Cardiol. 2008;31(11):516-20.

18. Poirier P, Martin J, Marceau P, Biron S, Marceau S. Impact of bariatric surgery on cardiac structure, function and clinical manifestations in morbid obesity. Expert Rev Cardiovasc Ther. 2004;2(2):193-201.

19. Cunha L de C, da Cunha CL, Souza AM, Chiminacio Neto N, Pereira RS, Suplicy HL. Evolutive echocardiographic study of the structural and functional heart alterations in obese individuals after bariatric surgery. Arq Bras Cardiol. 2006;87(5):615-22.

20. Alpert MA, Omran J, Bostick BP. Effects of obesity on cardiovascular hemodynamics, cardiac morphology, and ventricular function. Curr Obes Rep. 2016;5(4):424-34.

21. Aggarwal R, Harling L, Efthimiou E, Darzi A, Athanasiou T, Ashrafian $H$. The effects of bariatric surgery on cardiac structure and function: a systematic review of cardiac imaging outcomes. Obes Surg. 2016;26(5):1030-40.

22. Rodriguez Flores M, Aguilar Salinas C, Piché ME, Auclair A, Poirier P. Effect of bariatric surgery on heart failure. Expert Rev Cardiovasc Ther. 2017;15(8):567-79.

23. Yumuk V, Tsigos C, Fried M, Schindler K, Busetto L, Micic D, et al; Obesity Management Task Force of the European Association for the Study of Obesity. European guidelines for obesity management in adults. Obes Facts. 2015;8(6):402-24

24. Ponikowski P, Voors AA, Anker SD, Bueno H, Cleland JG, Coats AJ, et al; Authors/Task Force Members. 2016 ESC Guidelines for the diagnosis and treatment of acute and chronic heart failure: The Task Force for the diagnosis and treatment of acute and chronic heart failure of the European Society of Cardiology (ESC). Developed with the special contribution of the Heart Failure Association (HFA) of the ESC. Eur Heart J. 2016;37(27):2129-200. Erratum in: Erratum. Eur Heart J. 2016.

25. Rocha IE, Victor EG, Braga MC, Barbosa e Silva O, Becker MM. Echocardiography evaluation for asymptomatic patients with severe obesity. Arq Bras Cardiol. 2007;88(1):52-8. Erratum in: Arq Bras Cardiol. 2007;88(4):499.

26. Timoh T, Bloom ME, Siegel RR, Wagman G, Lanier GM, Vittorio TJ. A perspective on obesity cardiomyopathy. Obes Res Clin Pract. 2012;6(3):e175-262.

27. Murdolo G, Angeli F, Reboldi G, Di Giacomo L, Aita A, Bartolini C, et al. Left ventricular hypertrophy and obesity: only a matter of fat? High Blood Press Cardiovasc Prev. 2015;22(1):29-41.

28. Tavares IS, Sousa AC, Menezes Filho RS, Aguiar-Oliveira MH, BarretoFilho JA, Brito AF, et al. Left ventricular diastolic function in morbidly obese patients in the preoperative for bariatric surgery. Arq Bras Cardiol. 2012;98(4):300-6.

29. Anker SD, von Haehling S.The obesity paradox in heart failure: accepting reality and making rational decisions. Clin Pharmacol Ther. 2011;90(1):188-90.

30. Kunju SU, Badarudeen S, Schwarz ER. Impact of obesity in patients with congestive heart failure. Rev Cardiovasc Med. 2009;10(3):142-51.

31. Luaces M, Cachofeiro V, García-Muñoz-Najar A, Medina M, González $\mathrm{N}$, Cancer E, et al. Anatomical and functional alterations of the heart in morbid obesity. Changes after bariatric surgery. Rev Esp Cardiol (Engl Ed). 2012;65(1):14-21.

32. Leichman JG, Wilson EB, Scarborough T, Aguilar D, Miller CC 3rd, Yu S, et al. Dramatic reversal of derangements in muscle metabolism and left ventricular function after bariatric surgery. Am J Med. 2008;121(11):966-73.

33. Miranda WR, Batsis JA, Sarr MG, Collazo-Clavell ML, Clark MM, Somers VK, et al. Impact of bariatric surgery on quality of life, functional capacity, and symptoms in patients with heart failure. Obes Surg. 2013;23(7):1011-5.

34. Lim CP, Fisher OM, Falkenback D, Boyd D, Hayward CS, Keogh A, et al. Bariatric surgery provides a "bridge to transplant" for morbidly obese patients with advanced heart failure and may obviate the need for transplantation. Obes Surg. 2016;26(3):486-93.

35. Lyngbakken MN, Omland T, Nordstrand N, Norseth J, Hjelmesæth J, Hofsø D. Effect of weight loss on subclinical myocardial injury: a clinical trial comparing gastric bypass surgery and intensive lifestyle intervention. Eur J Prev Cardiol. 2016;23(8):874-80.

36. Kurnicka K, Domienik-Karłowicz J, Lichodziejewska B, Bielecki M, Kozłowska M, Goliszek S, et al. Improvement of left ventricular diastolic function and left heart morphology in young women with morbid obesity six months after bariatric surgery. Cardiol J. 2018;25(1):97-105.

37. Kardassis D, Bech-Hanssen O, Schönander M, Sjöström L, Karason K. The influence of body composition, fat distribution, and sustained weight loss on left ventricular mass and geometry in obesity. Obesity (Silver Spring). 2012;20(3):605-11

38. Kardassis D, Bech-Hanssen O, Schönander M, Sjöström L, Petzold $\mathrm{M}$, Karason K. Impact of body composition, fat distribution and sustained weight loss on cardiac function in obesity. Int J Cardiol. 2012;159(2):128-33

39. Aminian A, Jamal MH, Andalib A, Batayyah E, Romero-Talamás H, Chand B, et al. Is laparoscopic bariatric surgery a safe option in extremely high-risk morbidly obese patients? J Laparoendosc Adv Surg Tech A. 2015;25(9):707-11.

40. Vest AR, Schauer PR, Young JB. Failure and fatness: could surgical management of obesity reduce heart failure hospitalizations? J Am Coll Cardiol. 2016;67(8):904-6.

41. Tao W, Plecka-Östlund M, Lu Y, Mattsson F, Lagergren J. Causes and risk factors for mortality within 1 year after obesity surgery in a populationbased cohort study. Surg Obes Relat Dis. 2015;11(2):399-405. 
42. Nguyen NT, Masoomi H, Laugenour K, Sanaiha Y, Reavis KM, Mills SD, et al. Predictive factors of mortality in bariatric surgery: data from the Nationwide Inpatient Sample. Surgery. 2011;150(2):347-51.

43. Benotti P, Wood GC, Winegar DA, Petrick AT, Still CD, Argyropoulos $\mathrm{G}$, et al. Risk factors associated with mortality after Roux-en-Y gastric bypass surgery. Ann Surg. 2014;259(1):123-30.

44. Mehra MR, Canter CE, Hannan MM, Semigran MJ, Uber PA, Baran DA, et al; International Society for Heart Lung Transplantation (ISHLT) Infectious Diseases Council; International Society for Heart Lung Transplantation (ISHLT) Pediatric Transplantation Council; International Society for Heart Lung Transplantation (ISHLT) Heart Failure and Transplantation Council. The 2016 International Society for Heart Lung Transplantation listing criteria for heart transplantation: a 10-year update. J Heart Lung Transplant. 2016;35(1):1-23.

45. Ristow B, Rabkin J, Haeusslein E. Improvement in dilated cardiomyopathy after bariatric surgery. J Card Fail. 2008;14(3):198-202.

46. Wikiel KJ, McCloskey CA, Ramanathan RC. Bariatric surgery: a safe and effective conduit to cardiac transplantation. Surg Obes Relat Dis. 2014;10(3):479-84.
47. Samaras K, Connolly SM, Lord RV, MacDonald P, Hayward CS. Take heart: bariatric surgery in obese patients with severe heart failure. Two case reports. Heart Lung Circ. 2012;21(12):847-9.

48. Caceres M, Czer LS, Esmailian F, Ramzy D, Moriguchi J. Bariatric surgery in severe obesity and end-stage heart failure with mechanical circulatory support as a bridge to successful heart transplantation: a case report. Transplant Proc. 2013;45(2):798-9.

49. Chaudhry UI, Kanji A, Sai-Sudhakar CB, Higgins RS, Needleman BJ. Laparoscopic sleeve gastrectomy in morbidly obese patients with endstage heart failure and left ventricular assist device: medium-term results. Surg Obes Relat Dis. 2015;11(1):88-93.

50. Jeng EI, Aranda JM Jr, Ahmed M, Klodell CT. Left ventricular assist device and bariatric surgery: a bridge to heart transplant by weight and waiting time reduction. J Card Surg. 2016;31(2):120-2.

51. Greene J, Tran T, Shope T. Sleeve gastrectomy and left ventricular assist device for heart transplant. JSLS. 2017;21(3):pii:e2017.00049.

52. Leviner DB, Keidar A, Ben-Gal T, Medalion B. Cardiac function recovery following LVAD implantation and bariatric surgery in a morbidly obese patient. J Card Surg. 2014;29(5):740-2. 